\title{
Analisis Stabilitas Lereng dan Alternatif Penanganan Kelongsoran Studi Kasus Ruas Jalan Ir. H. Nursyirwan Ismail, Kota Samarinda
}

\author{
Helmy Darjanto ${ }^{1, *}$, Himatul Farichah ${ }^{2}$, Rosy Lumintang ${ }^{3}$ \\ Teknik Sipil, Universitas Narotama, Surabaya ${ }^{1}$, Teknik Sipil, Universitas Pembangunan Nasional Veteran Jawa Timur, Surabaya ${ }^{2}$, Departe- \\ men Teknik Infrastruktur Sipil, Institut Teknologi Sepuluh Nopember, Surabaya ${ }^{3}$ \\ Koresponden*, Email: hdarjanto@gmail.com
}

\begin{tabular}{|c|c|c|}
\hline & Info Artikel & Abstract \\
\hline Diajukan & 19 Januari 2021 & Slope failure occurred on the Ir. H. Nursyirwan Ismail, Ring Road II, Samarinda city, Kali- \\
\hline Diperbaiki & 17 Mei 2021 & mantan. Slope failure occurs at two points which will be referred as slope 1 and slope 2 . The \\
\hline Disetujui & 06 Juni 2021 & $\begin{array}{l}\text { purpose of this study is to analyze the stability of slope and alternative of slope reinforcements } \\
\text { using piles and sheet pile. Soil investigation data is utilized to analyze slope stability modeling } \\
\text { with Finite Element method which is performed in the Plaxis V.8.2. The analysis of slope re- } \\
\text { inforcement using a } 25 x 25 \text { mini pile on slope } 1 \text { shows } S F=2.04 \text { and deformation }=26.17 x 10^{-} \\
3 \text { m. Furthermore, on slope } 2 \text { shows } S F=2.04 \text { and deformation }=35.09 x 10^{-3} \text { m. Whereas for }\end{array}$ \\
\hline $\begin{array}{l}\text { Keywords: } \\
\text { method. }\end{array}$ & , slope, finite element & $\begin{array}{l}\text { reinforcement } S \text { Sing sheet reinforced concrete }(F C P) \text { with type } F(P-220-6 S-A \text {, on slope I pro- } \\
\text { duces } S .05 \text { and deformation of } 37.01 \times 10^{-3} \mathrm{~m} .\end{array}$ \\
\hline
\end{tabular}

Abstrak

Kelongsoran terjadi pada ruas jalan Ir. H. Nursyirwan Ismail, Ring Road II, kota Samarinda, Kalimantan. Kelongsoran tersebut terjadi pada dua titik yang diselanjutnya akan disebut lereng 1 dan lereng 2 . Tujuan dari penelitian ini adalah untuk menganalisa stabilitas lereng dan alternatif penanganan kelongsoran menggunakan pile dan sheet pile. Data penyelidikan tanah digunakan untuk melakukan analisa pemodelan kestabilan lereng dengan metode Elemen Hingga pada program bantu Plaxis V.8.2. Hasil analisis perbaikan lereng menggunakan soldier mini pile 25x25, pada lereng 1 menghasilkan SF 2.04 dan deformasi $26.17 \times 10^{-3} \mathrm{~m}$. Sedangkan pada lereng 2, didapatkan SF 2.04 dan deformasi $35.09 \times 10^{-3} \mathrm{~m}$. Selanjutnya untuk perbaikan menggunakan flat sheet pile concrete $(\mathrm{FCP})$ dengan tipe FCP-220-6S-A, pada lereng 1 menghasilkan SF 2.02 dan deformasi $28.35 \times 10^{-3}$

Kata kunci: stabilitas, lereng, metode finite elemen m. Sedangkan untuk lereng 2, didapatkan SF 2.05 dan deformasi $37.01 \times 10^{-3} \mathrm{~m}$.

\section{Pendahuluan}

Jalan Ir. H. Nursyirwan Ismail, Ring Road II terletak di kota Samarinda, Kalimantan. Jalan tersebut menghubungkan Jalan Suryanata-Loa bahu. Pada bulan Juli di tahun 2020, terjadi kelongsoran pada ruas jalan tersebut. Kelongsoran terjadi pada dua titik. Selanjutnya untuk kelongsoran titik 1 akan disebut lereng 1 dan kelongsoran titik 2 akan disebut lereng 2. Kelongsoran pada titik pertama terjadi sepanjang 18 m. Sedangkan pada titik kedua terjadi sepanjang $17.5 \mathrm{~m}$ seperti pada Gambar 1.

Kestabilan lereng bisa ditingkatkan dengan berbagai cara. Salah satunya adalah dengan meningkatkan gaya penahan melalui adahnya struktur penahan tanah dengan menggunakan dinding atau tiang. Di Indonesia, ada beberapa konstruksi penahan tanah yang bisa digunakan sebagai penanggulangan kelongsoran, salah satunya adalah dengan menggunakan pile atau sheet pile. Pile telah banyak berhasil diaplikasikan sebagai konstruksi untuk stabilisasi lereng atau meningkatkan stabilitas lereng [1] [2] [3], dan banyak metode yang sudah dikembangkan terkait hal tersebut. Abdelaziz dkk [4] juga melakukan studi pada 28 lokasi di tahun 1988 hingga 2011 mengenai perkuatan lereng menggunakan pile. Pile digunakan dalam stabilisasi lereng untuk menahan gaya lateral akibat pergerakan horizontal lereng. Begitu juga dengan sheet pile, banyak peneliti yang sudah melakukan studi terkait sheet pile untuk stabilisasi lereng [5] [6] [7].

Banyak penelitian yang telah dilakukan untuk metode analisis stabilitas lereng. Diantaranya yaitu finite element method, FEM [1], discrete element method, DEM [8], dan limit equilibrium method, LEM seperti metode Bishop [9], metode Janbu modifikasi [10]. Masing-masing metode memiliki kelebihan dan kekurangan. Dengan menggunakan FEM, permasalahan geoteknik yang kompleks dapat diselesaikan dengan baik dan akurat [11]. Selain itu, FEM merupakan pendekatan yang paling komprehensif untuk pile sebagai stabilisasi lereng karena mampu secara bersamaan memodelkan perilaku pile dan stabilita lereng [1]. Hal tersebut tentu saja berlaku juga untuk memodelkan sheet pile. 


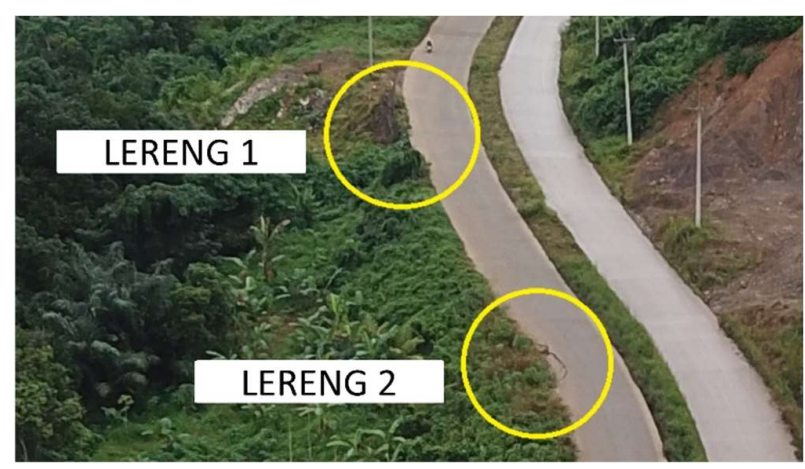

Gambar 1. Titik kelongsoran pada ruas jalan Ir. H. Nursyirwan Ismail, Ring Road II.

Diantara banyaknya metode FEM yang dikembangkan belakangan ini, disebutkan bahwa strength reduction method [12] lebih disarankan untuk analisis stabilitas lereng yang tidak dalam masa konstruksi [11]. Pada strength reduction method, parameter kuat geser tanah akan diturunkan hingga lereng menjadi tidak stabil. Jika potensi stabilitas lereng terhadap kelnogsoran dinyatakan dengan nilai faktor keamanan (SF). Maka dengan menggunakan strength reduction factor, nilai SF akan didapatkan dari rasio antara parameter kuat geser inisial dan ketika kritis. Faktor keamanan lereng yang disyaratkan untuk analisis kestabilan lereng tanah dengan didasarkan pada pertimbangan biaya dan konsekuensi kegagalan lereng terhadap tingkat ketidakpastian kondisi analisis. Dalam hal ini nilai faktor keamanan dipersyaratkan SF $>1.5$ [13].

Oleh karena itu, dalam studi ini dilakukan analisis stabilitas lereng dan alternatif penanganan longsor dengan pile dan sheet pile pada Jalan Ir. H. Nursyirwan Ismail, Ring Road II, Kota Samarinda, Provinsi Kalimantan. dengan menggunakan FEM yang dimodelkan menggunakan program bantu Plaxis $2 \mathrm{D}$.

\section{Metode}

Langkah-langkah atau metode penelitian pada studi ini adalah sebagai berikut:

1. Start.

2. Lokasi studi ini berada di ruas jalan Ir. H. Nursyirwan Ismail, Ring Road II, Kota Samarinda, Provinsi Kalimantan. Pada lokasi tersebut dilakukan pengumpulan data primer dengan mengumpulkan informasi dan dokumentasi yang berupa:

a. Foto dan sketsa kelongsoran

b. Data borlog dan $N_{\text {SPT }}$ dari hasil pengujian di lapangan

c. Data hasil geolistrik
3. Selanjutnya dilakukan pembuatan stratigrafi tanah atau pembagian lapisan tanah berdasarkan nilai $\mathrm{N}_{S P T}$ dan konsistensi tanah.

4. Pada tahap ini dilakukan pemodelan geometri lereng di menggunakan FEM dengan program Plaxis V.8.2. Plaxis (Finite Elemen Code for Soil and Rock Analyses) merupakan suatu rangkuman program elemen hingga yang telah dikembangkan untuk menganalisis deformasi dan stabilisasi geoteknik dalam perencanaan-perencanaan sipil [14]. Untuk input parameter di Plaxis maka dilakukan analisis dan interpretasi data yang didapatkan pada poin 2. Dilakukan korelasi empiris untuk mendapatkan semua parameter input di Plaxis. Nilai $N_{\text {SPT }}$ dan hasil penyelidikan boring yang memberikan informasi jenis tanah dikorelasi untuk mendapatkan konsistensi tanah, nilai berat volume $(\gamma)$, berat volume jenuh $\left(\gamma_{\text {sat }}\right)$, kohesi $\left(C_{\mathrm{u}}\right)$, sudut geser $(\varphi)$, modulus elastisitas $(\mathrm{E})$, permeabilitas $(\mathrm{k})$, dan poisson ratio $(\mathrm{v})$.

5. Setelah dilakukan pemodelan geometri di Plaxis dengan parameter input dari hasil korelasi. Maka dilakukan back analysis untuk menverifikasi parameter input yang digunakan pada poin 3. Metode back analysis dapat digunakan untuk mendapatkan parameter kuat geser tanah (kohesi dan sudut geser) dengan asumsi SF sama dengan 1, yaitu kondisi disaat lereng mengalami kegagalan. Back analysis ini dilakukan untuk kedua lereng, baik lereng 1 maupun lereng 2 .

6. Setelah dilakukan back analysis maka didapatkan parameter input yang digunakan untuk perencanaan perbaikan longsor dengan sheet pile. Sheet pile dimodelkan dengan pendekatan material plate di Plaxis. Pada tahap ini dapat diketahui bagaimana nilai SF, pola keruntuhan dan deformasi yang terjadi pada dinding sheet pile.

7. Dengan input parameter yang sama dengan poin 5, dilakukan perencanaan perbaikan longsor dengan mini pile. Mini pile dimodelkan dengan pendekatan material plate di Plaxis. Pada tahap ini dapat diketahui bagaimana nilai SF, pola keruntuhan dan deformasi yang terjadi pada dinding mini pile.

8. Hasil dari poin 5 dan 6 digunakan sebagai dasar untuk merumuskan kesimpulan dan saran pada studi ini.

9. Finish.

\section{Hasil dan Pembahasan \\ Kondisi lereng di lokasi penelitian}

- Terdapat dua titik kelongsoran pada lokasi penelitian. Longsor pada lereng 1 seperti terlihat pada Gambar 2. Sedangkan longsor pada lereng 2 terlihat pada Gambar 3. 




Gambar 2. Longsor pada lereng 1

- Berdasarkan hasil penyelidikan tanah borlog diketahui bahwa material tanah pada lokasi tersebut adalah pasir, lempung, lanau, hard clay dan hard sand pada lereng 1 1 maupun 2. Data $N_{\text {SPT }}$ dan stratigrafi dapat dilihat pada Gambar 4 dan Gambar 5 untuk lereng 1 dan 2 secara berurutan.



Gambar 3. Longsor pada lereng 2

- Pengukuran data geolistrik dilakukan untuk empat lintasan. Untuk lereng 1 lintasan TL1_LA \& TL1_LB dan untuk lereng 2 TL2_LA \& TL2_LB sesuai dengan garis berwarna biru pada Gambar 6. Dari hasil pengukuran data tersebut, berdasarkan sifat kelistrikan, zona lemah memiliki nilai resistivitas rendah $(<30 \Omega$.m) dan chargeability rendah $(<40 \mathrm{msec})$. Dengan demikian diperoleh hasil analisis zona lemah pada setiap lintasan sebagai mana yang terlihat pada Gambar 7, Gambar 8, Gambar 9 dan Gambar 10. Zona lemah tersebar menerus dari bagian median jalan sampai ke bagian pinggir jalan. Letak zona lemah pada lintasan pengukuran geolistrik dapat dilihat sebagai garis berwarna merah pada Gambar 6. Perlu diketahui bahwa area yang berwarna merah muda menunjukkan zona kelongsoran untuk lereng 1 dan lereng 2 .

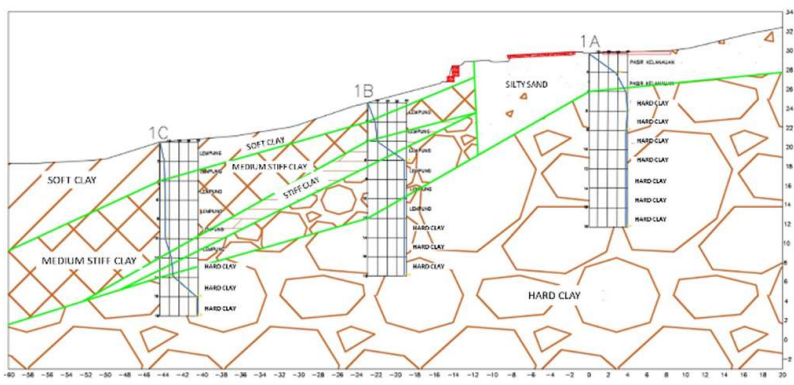

Gambar 4. Stratigrafi pada Lereng 1

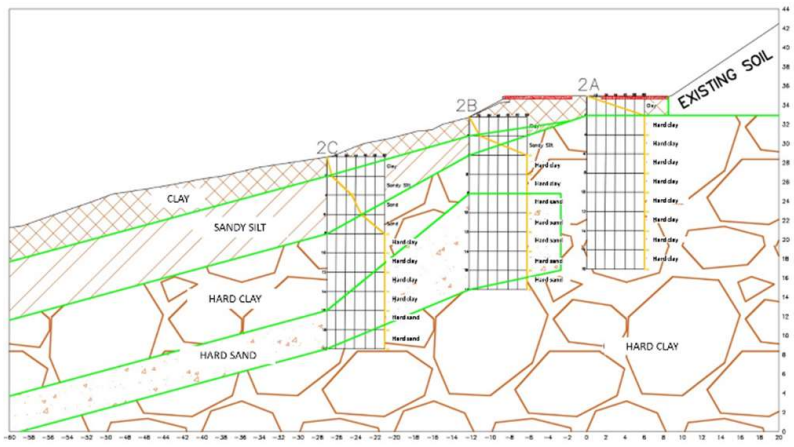

Gambar 5. Stratigrafi pada Lereng 2

\section{Back Analysis}

Back analysis dilakukan untuk menverifikasi input parameter yang digunakan dalam pemodelan FEM di Plaxis. Geometri lereng dimodelkan sesuai dengan detail potongan lereng yang didapatkan dari gambar kerja. Geometri lereng yang dimodelkan pada Plaxis 8.2 dapat dilihat pada Gambar 11 dan Gambar 13 untuk lereng 1 dan 2 secara berurutan. Material tanah penyusun lereng tersebut dimodelakan menggunakan model keruntuhan Mohr-Coulomb. Beban lalu lintas jalan dimodelkan sebagai distributed load sebesar 15 $\mathrm{kN} / \mathrm{m}^{2}$ (Panduan Geoteknik 4).

Hasil analisis lereng 1 dan lereng 2 pada Gambar 12 dan Gambar 14, berurutan, menggunakan Plaxis 8.2 didapatkan bahwa bidang longsor menyerupai bidang longsor yang terjadi di lapangan baik untuk lereng 1 maupun lereng 2. Secara berurutan SF yang didapat untuk lereng 1 dan lereng 2 adalah 1.05 dan 1.07. Sehingga input parameter data tanah dianggap bisa digunakan untuk perencanaan perbaikan lereng yang akan dibahas pada sub pembahasan berikutnya. 


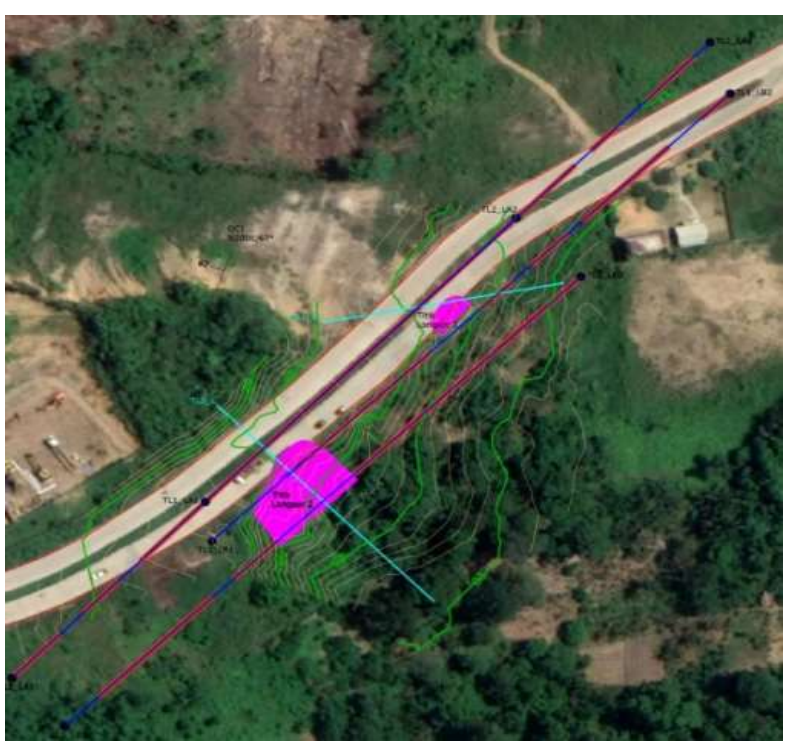

Gambar 6. Lokasi pengambilan data geolistrik

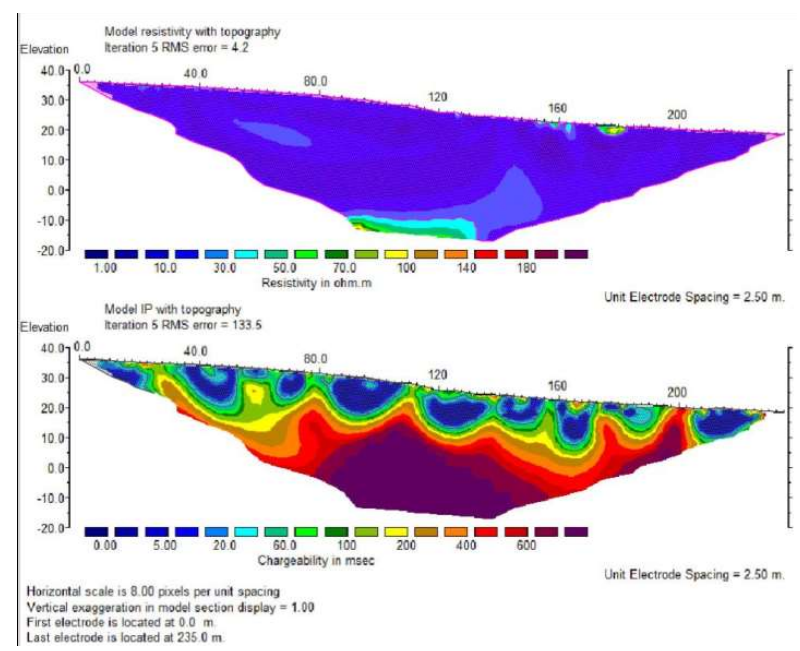

Gambar 7. Zona lemah berdasarkan nilai resistivitas dan chargeability pada Lintasan TL1_LA

\section{Alternatif penanganan kelongsoran \\ Pile}

Salah satu alternatif yang digunakan dalam penanganan longsor adalah pile. Pile yang digunakan termasuk mini pile dengan ukuran soldier mini pile 25×25 dengan detail material seperti pada Tabel 1. Mini pile digunakan dengan jarak 3D yaitu $0.75 \mathrm{~m}$ dengan capping beam $0.3 \mathrm{~m}$. Mini pile dengan panjang $6 \mathrm{~m}$ tersebut dipasang untuk memperkuat kedua lereng.

Hasil analisis dapat dilihat pada Gambar 15. Untuk lereng 1 (Gambar 15. a), deformasi maksimal mini pile yang dihasilkan adalah $26.17 \times 10^{-3} \mathrm{~m}$ dengan $\mathrm{SF}=2.04$. Sedangkan untuk lereng 2 (Gambar 15. b), deformasi maksimal mini pile yang dihasilkan adalah $35.09 \times 10^{-3} \mathrm{~m}$ dengan $\mathrm{SF}=2.04$. Batas toleransi defleksi dinding diambil $0.5 \% \mathrm{H}$ dimana $54.5 \times 10^{-3} \mathrm{~m}$ dan $70.05 \times 10^{-3} \mathrm{~m}$ secara berurutan untuk lereng 1 dan lereng 2.

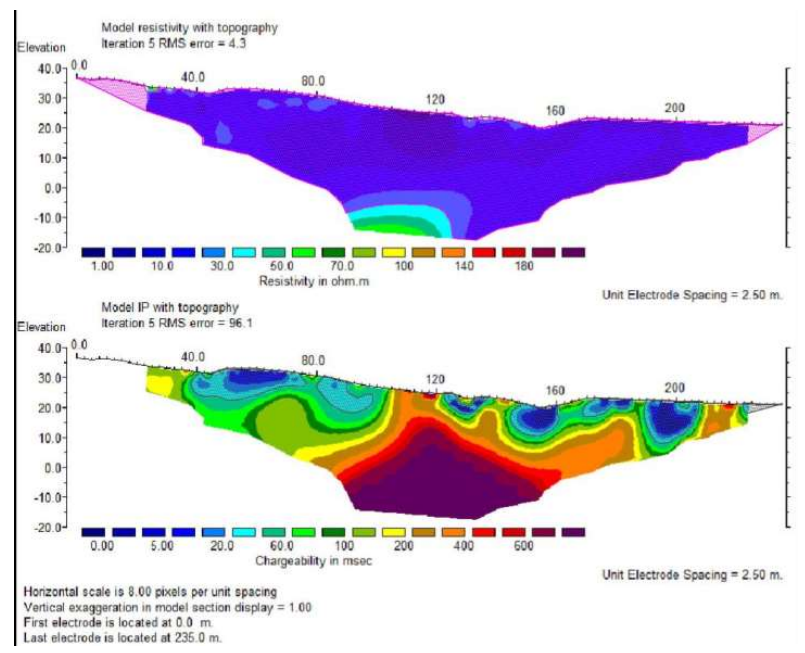

Gambar 8. Zona lemah berdasarkan nilai resistivitas dan chargeability pada Lintasan TL1_LB



Gambar 9. Zona lemah berdasarkan nilai resistivitas dan chargeability pada Lintasan TL2_LA

Tabel 1. Properti material perkuatan

\begin{tabular}{cccccc}
\hline $\begin{array}{c}\text { Jenis } \\
\text { flat sheet } \\
\text { pile }\end{array}$ & $\begin{array}{c}\text { Type } \\
\text { FCP- }\end{array}$ & $\begin{array}{c}\mathrm{EA} \\
(\mathrm{kN} / \mathrm{m})\end{array}$ & $\begin{array}{c}\mathrm{EI} \\
\left(\mathrm{kN} / \mathrm{m}^{2} / \mathrm{m}\right)\end{array}$ & $\begin{array}{c}\mathrm{W} \\
\mathrm{kN} / \mathrm{m} / \mathrm{m})\end{array}$ & $v$ \\
$\begin{array}{c}\text { concrete } \\
\text { (FCP) }\end{array}$ & A & & & & \\
$\begin{array}{c}\text { Mini pile } \\
\text { Capping } \\
\text { beam }\end{array}$ & $25 \times 25$ & $1.31 \mathrm{E}+06$ & $6.8 \mathrm{E}+03$ & 0.6 & 0.25 \\
\hline
\end{tabular}






Gambar 10. Zona lemah berdasarkan nilai resistivitas dan chargeability pada Lintasan TL1_LB

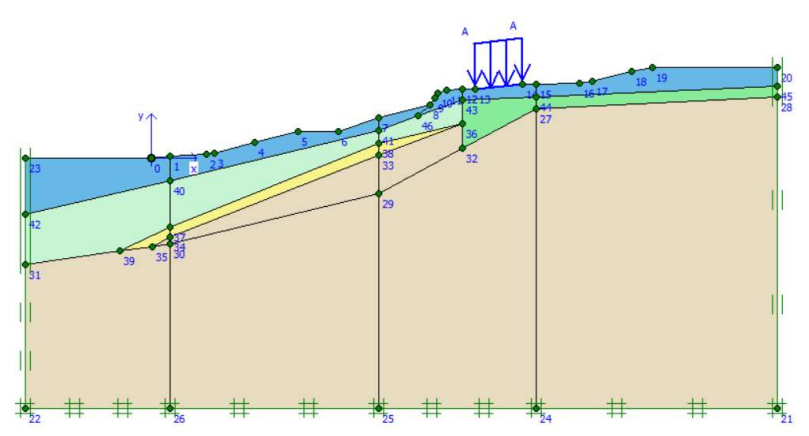

Gambar 11. Geometri lereng 1

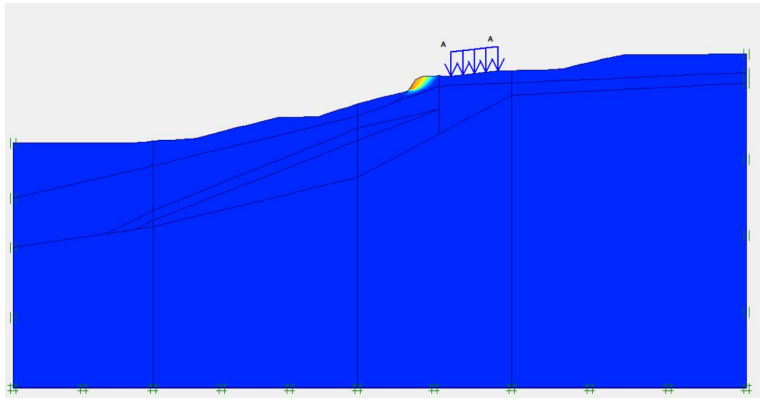

Gambar 12. Back analysis lereng 1

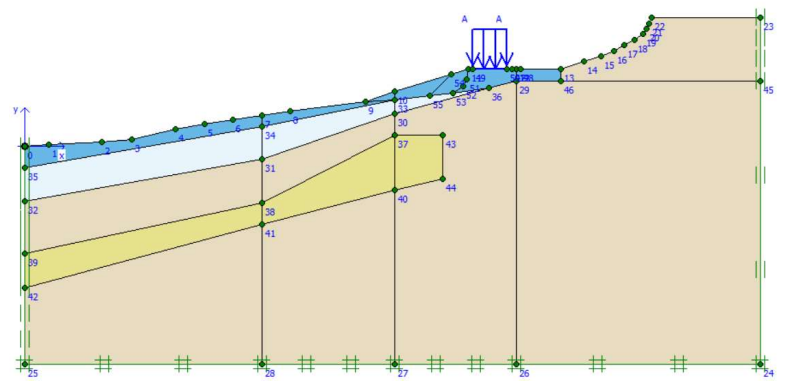

Gambar 13. Geometri lereng 2



Gambar 14. Back analysis lereng 2 (tampilan zoom in)

\section{- Sheet pile}

Alternatif yang digunakan sebagai penanganan kelongsoran adalah pile dan sheet pile. Pada studi ini, sheet pile yang digunakan adalah jenis flat sheet pile concrete (FCP) dengan tipe FCP-220-6S-A dengan detail material seperti pada Tabel 1. FCP dengan Panjang $6 \mathrm{~m}$ dipasang untuk memperkuat kedua lereng.

Hasil analisis seperti pada Gambar 16. Untuk lereng 1 (Gambar 16.a), deformasi maksimal sheet pile yang dihasilkan adalah $28.35 \times 10^{-3} \mathrm{~m}$ dengan $\mathrm{SF}=2.02$. Sedangkan untuk lereng 2 (Gambar 16.b), deformasi maksimal sheet pile yang dihasilkan adalah $37.01 \times 10^{-3} \mathrm{~m}$ dengan $\mathrm{SF}=2.05$. Deformasi yang terjadi pada lereng 2 lebih besar dibandingkan dengan lereng 1 bisa terjadi karena lereng 2 memang memiliki tinggi (H) yang lebih besar dibandingkan dengan lereng 1 .

\section{Simpulan}

Analisa stabilitas lereng dengan menggunakan Finite Elemen Method telah digunakan untuk menilai stabilitas lereng dan alternatif perbaikan kelongsoran pada Jalan Ir. H. Nursyirwan Ismail, Ring Road II terletak di kota Samarinda, Kalimantan dapat disimpulkan bahwa telah dilakukan analisis perbaikan lereng dan perbaikan kelongsoran menggunakan pile dan sheet pile yang dimodelkan dengan Plaxis.

Perbaikan kelongsoran untuk lereng 1 telah dilakukan menggunakan mini pile 25x25 menghasilkan SF 2.04 dan deformasi $26.17 \times 10^{-3} \mathrm{~m}$. Sedangkan untuk lereng 2, didapatkan SF 2.04 dan deformasi $35.09 \times 10^{-3} \mathrm{~m}$. Perbaikan kelongsoran untuk lereng 1 telah dilakukan dengan flat sheet pile concrete (FCP) dengan tipe FCP-220-6S-A menghasilkan SF 2.02 dan deformasi $28.35 \times 10^{-3} \mathrm{~m}$. Sedangkan untuk lereng 2, didapatkan SF 2.05 dan deformasi $37.01 \times 10^{-3} \mathrm{~m}$.

\section{Daftar Pustaka}

[1] E. Ausilio, E. Conte dan G. Dente, "Stability analysis of slopes reinforced with piles," Computers and Geotechnics, vol. 28, no. 8, pp. 591-611, 2001. 
[2] T. Hull dan H. G. Poulos, "Design Method for Stabilization of Slopes with Piles," Journal of Geotechnical and Geoenvironmental Engineering, vol. 125, pp. 910-914, 1999.

[3] F. Cai dan K. Ugai, "Numerical Analysis of the Stability of a Slope Reinforced with Piles," Soils and Foundations, vol. 40, no. 1, pp. 73-84, 2000.

[4] T. S. Abdulaziz, D. W. Proudfoot dan R. Skirrow, "Stabilization of Alberta highway landslides using pile walls," Proceeding of the 2011 Pan-am CGS Geotechnical Conference, 2011.

[5] J. R. Bartz, "Analysis and Design of Sheet Pile Ribs for Slope Stabilization," University of Alberta, Canada, 2017.

[6] J. R. Bartz, C. D. Martin dan M. T. Hendry, "Design Procedure for Landslide Stabilization Using Sheet Pile Ribs," Canadian Geotechnical Journal, vol. 56, no. 4, pp. 514-525, 2018.

[7] R. Hassani dan R. Basirat, "Classical Method and Numerical Modeling for Designing of Sheet Pile Wall (Case Study: Tuti-Bahri Bridge, Sudan)," dalam 3rd International Conference on Modern Research in Civil Engineering, Architectural and Urban Development, Berlin, 2016.

[8] P. A. Cundal dan O. D. L. Strack, "A discrete numerical model for granular assemblies," Géotechnique, vol. 29, no. 1, pp. 47-65, 1979.

[9] A. W. Bishop, "The use of the Slip Circle in the Stability Analysis of Slopes," Géotechnique, vol. 5, no. 1, pp. 7-17, 1955.

[10] N. Janbu, “ Application of composite slip surfaces for stability analysis," dalam Proceedings of European conference on stability of earth slopes, Stockholm, 1954.

[11] W. Alkasawneh, A. I. H. Malkawi, J. H. Nusairat dan N. Albataineh, "A comparative study of various commercially available programs," Computers and Geotechnics, vol. 35, no. 3, pp. 428-435, 2008.

[12] T. Matsui dan K. C. San, "Finite Element Slope Stability Analysis by Shear Strength Reduction Technique," Soils and Foundations, vol. 32, no. 1, pp. 59-70, 1992.

[13] SNI:8460, "Persyaratan perancangan geoteknik," Badan Standardisasi Nasional, Jakarta, 2017.

[14] Plaxis, "Tutorial Manual," A.A. Balkema, Rotterdam, 2012.



a) Lereng 1

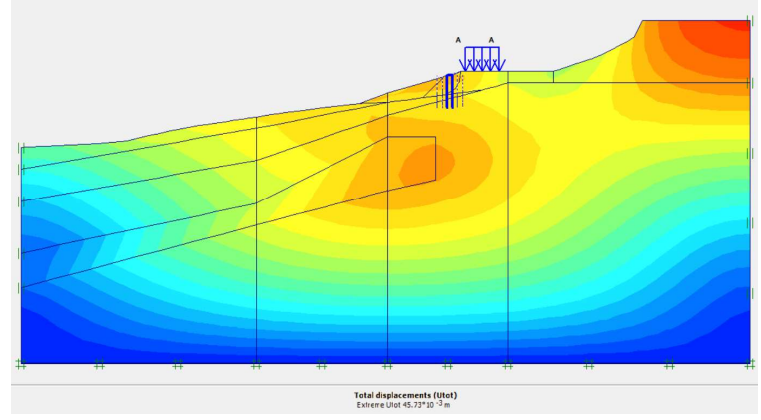

b) Lereng 2

Gambar 15. Hasil analisis perkuatan mini pile

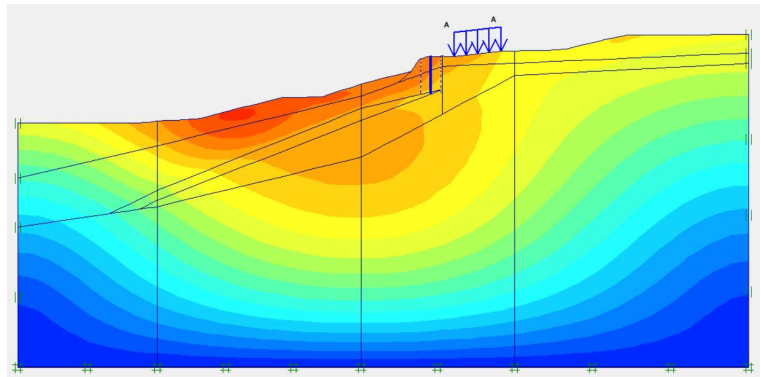

a) Lereng 1

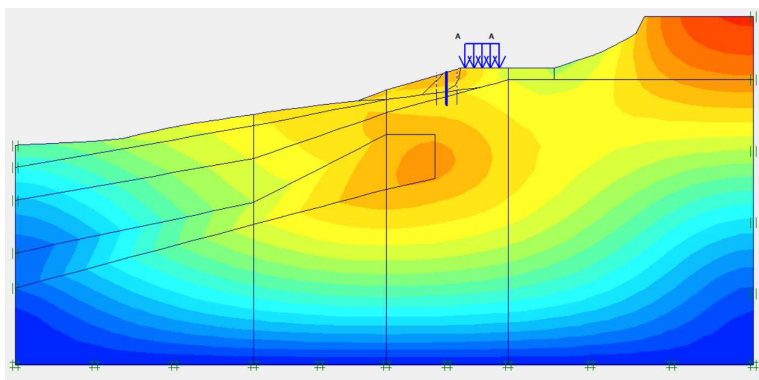

b) Lereng 2

Gambar 16. Hasil analisis perkuatan sheet pile 